Felix C. Tanner

Bernd van der Loo

Sidney Shaw

Helen Greutert

Markus M. Bachschmid

Maria Berrozpe

Izabela Rozenberg

Nenad Blau

Robert Siebenmann

Jürg Schmidli

Peter Meyer

Thomas F. Lüscher

\section{Inactivity of nitric oxide synthase gene in the atherosclerotic human carotid artery}

Received: 3 January 2007

Returned for 1. revision: 30 January 2007

1. Revision received: 23 February 2007

Accepted: 26 February 2007

Published online: 15 March 2007
F. C. Tanner, MD · B. van der Loo, MD ·

H. Greutert - M. Berrozpe, $\mathrm{PhD}$.

I. Rozenberg · T. F. Lüscher, MD

Cardiovascular Research, Physiology

Institute

University of Zürich

Zürich, Switzerland

F. C. Tanner, MD · I. Rozenberg ·

T. F. Lüscher, MD

Center for Integrative Human Physiology

University of Zürich

Zürich, Switzerland

S. Shaw, PhD

Dept. of Clinical Research, University

Hospital

Bern, Switzerland

M. M. Bachschmid, PhD

Dept. of Biology, University of Konstanz

Konstanz, Germany

N. Blau, PhD

Clinical Chemistry, University Children's Hospital

Zürich, Switzerland

\author{
R. Siebenmann, MD \\ Cardiovascular Surgery \\ Herzzentrum Hirslanden \\ Zürich, Switzerland \\ J. Schmidli, MD \\ Cardiovascular Surgery, University Hospital \\ Bern, Switzerland \\ P. Meyer, MD \\ Ophthalmology, University Hospital \\ Basel, Switzerland
}

\author{
F. C. Tanner, MD · B. van der Loo, MD • T. F. \\ Lüscher, MD $(\varangle)$ \\ Cardiology, Cardiovascular Center \\ University Hospital \\ Rämistraße 100 \\ 8091 Zürich, Switzerland \\ Tel.: + 41-1/255-2121 \\ Fax: + 41-1/255-4251 \\ E-Mail cardiotfl@gmx.ch
}

Abstract Objective Nitric oxide (NO) inhibits thrombus formation, vascular contraction, and smooth muscle cell proliferation. We investigated whether NO release is enhanced after endothelial NO synthase (eNOS) gene transfer in atherosclerotic human carotid artery ex vivo. Methods and Results Western blotting and immunohistochemistry revealed that transduction enhanced eNOS expression; however, neither nitrite production nor NO release measured by porphyrinic microsensor was altered. In contrast, transduction enhanced NO production in non-atherosclerotic rat aorta and human internal mammary artery. In transduced carotid artery, calcium-dependent eNOS activity was minimal and did not differ from control conditions. Vascular tetrahydrobiopterin concentrations did not differ between the experimental groups. Treatment of transduced carotid artery with FAD, FMN, NADPH, L-arginine, and either sepiapterin or tetrahydrobiopterin did not alter NO release. Superoxide formation was similar in transduced carotid artery and control. Treatment of transduced carotid artery with superoxide dismutase (SOD), PEG-SOD, PEG-catalase did not affect NO release. Conclusions eNOS transduction in atherosclerotic human carotid artery results in high expression without any measurable activity of the recombinant protein. The defect in the atherosclerotic vessels is neither caused by cofactor deficiency nor enhanced NO breakdown. Since angioplasty is performed in atherosclerotic arteries, eNOS gene therapy is unlikely to provide clinical benefit.

Key words Nitric oxide synthase - gene therapy - adenoviral vector atherosclerosis - endothelium 


\section{List of abbreviations}

\begin{tabular}{|c|c|}
\hline AdeNOS & $\begin{array}{l}\text { adenoviral vector for expression of } \\
\text { human eNOS }\end{array}$ \\
\hline AdhPAP & $\begin{array}{l}\text { adenoviral vector for expression of } \\
\text { human placental alkaline phosphatase }\end{array}$ \\
\hline ADMA & asymmetric dimethylarginine \\
\hline $\mathrm{BH}_{4}$ & tetrahydrobiopterin \\
\hline $\mathrm{CA}$ & carotid arteries \\
\hline DMEM & dulbecco's modified eagle medium \\
\hline DTT & dithiothreitol \\
\hline EDTA & ethylenediaminetetraacetic acid \\
\hline EDRF & endothelium-derived relaxing factor \\
\hline EGTA & ethylene glycol tetraacetic acid \\
\hline eNOS & endothelial NO synthase \\
\hline FAD & flavin adenine dinucleotide \\
\hline FCS & fetal calf serum \\
\hline FITC & fluorescein isothiocyanate \\
\hline FMN & flavin mononucleotide \\
\hline hPAP & human placental alkaline phosphatas \\
\hline iNOS & inducible nitric oxide synthase \\
\hline L-NAME & $\mathrm{N}(\mathrm{G})$-nitro-L-arginine methyl ester \\
\hline MA & internal mammary artery \\
\hline NADPH & $\begin{array}{l}\text { nicotine adenine dinucleotide phos- } \\
\text { phate }\end{array}$ \\
\hline NMA & N-monomethylarginine \\
\hline nNOS & neuronal nitric oxide synthase \\
\hline NO & Nitric oxide \\
\hline $\mathrm{NO}_{2}^{-}$ & nitrite \\
\hline $\begin{array}{l}\mathrm{O}_{2}^{-} \\
\mathrm{oxLDL}\end{array}$ & $\begin{array}{l}\text { superoxide } \\
\text { oxidized low density lipoprotein }\end{array}$ \\
\hline PEG-catalase & polyethylene glycol catalase \\
\hline PEG-SOD & $\begin{array}{l}\text { polyethylene glycol superoxide dis- } \\
\text { mutase }\end{array}$ \\
\hline PVDF & polyvinylidene fluoride \\
\hline SDS-PAGE & $\begin{array}{l}\text { SDS-polyacrylamide gel electro- } \\
\text { phoresis }\end{array}$ \\
\hline & superoxide dismutase \\
\hline & vascular smooth muscle cell \\
\hline
\end{tabular}

\section{Introduction}

Gene therapy is a promising therapeutic approach for restenotic lesions, and for in-stent-restenosis in particular $[21,32]$. Nitric oxide (NO) inhibits platelet aggregation, induces vascular relaxation, and impairs vascular smooth muscle cell (VSMC) proliferation by specific actions on cell cycle progression [11,12,25]. Moreover, NO counterregulates the induction of adhesion molecule expression and leucocyte accumulation as well as other inflammatory alterations occurring in atherosclerotic arteries [3]. Therefore, overexpression of endothelial NO synthase (eNOS) seems a reasonable concept for the local treatment of restenotic lesions. This is particularly plausible as balloon dilatation is performed in athero- sclerotic vessels which exhibit reduced eNOS expression [17].

NO formation is catalyzed by at least 3 different isoforms of NOS. Neuronal NOS is constitutively expressed in neurons and some other cell types; it generates low levels of NO. Expression of inducible NOS (iNOS) can be induced by cytokines in many different cell types; this isoform generates high levels of NO. Endothelial NOS is constitutively expressed in endothelial cells and some other cell types, and similar to nNOS, it releases low levels of NO. The major reason responsible for the different enzyme kinetics is the calcium-dependency of nNOS and eNOS [9].

Normal function of eNOS is critically dependent on the availability of the substrate L-arginine and several cofactors as well. Indeed, L-arginine administration increases endothelial NO synthesis in hypercholesterolemia [7], and tetrahydrobiopterin $\left(\mathrm{BH}_{4}\right)$ infusion restores endothelium-dependent relaxation in hypercholesterolemic humans [22]. In addition, reduced NO activity may not only be caused by diminished synthesis, but also by enhanced catabolism of the radical, as the half-life of NO is determined by its reaction with oxyhemoglobin and superoxide $\left(\mathrm{O}_{2}^{-}\right)$[31]. Thus, atherosclerotic arteries may have a diminished NO production because of both reduced cofactor concentration and enhanced $\mathrm{O}_{2}{ }^{-}$production [18]. As treatment of restenosis by gene delivery would have to be performed in such diseased vessels, we examined whether eNOS transduction into atherosclerotic human carotid arteries (CA) ex vivo is indeed followed by an enhanced NO production.

\section{Methods}

\section{Recombinant adenovirus}

An adenoviral vector for expression of human placental alkaline phosphatase (AdhPAP) was prepared as described [19]. The vector for expression of eNOS (AdeNOS) was provided by Dr Stefan Janssens, Leuven, Belgium [1]. The titer of purified viruses was determined by plaque assay on 293 cells as described [14]. Viral titers ranged from $2 \times 10^{10}$ to $2 \times 10^{11} \mathrm{pfu} / \mathrm{ml}$ for all preparations. The titer of wild type virus was determined by plaque assay on A549 cells using the same conditions and was below 1 in $10^{9} \mathrm{pfu} / \mathrm{ml}$.

\section{Cell culture, tissue culture, transduction}

293 cells and A549 cells were obtained from ATCC and cultured as recommended. CA tissue specimens were obtained from 50 human donors undergoing endarterectomy. The study was reviewed by the ethics committee of the University Hospital, and the patients 
gave their informed consent prior to inclusion in the study. Mean age was $71 \pm 8$; males: $72 \%$; smokers: $52 \%$; hypercholesterolemia; $56 \%$; hypertension: $70 \%$; diabetes: $34 \%$. $86 \%$ of patients were treated with aspirin, $64 \%$ with a statin. No difference between eNOS expression, risk factors, and specific medication was observed in the CA specimens. All specimens exhibited macroscopic evidence of atherosclerotic changes (fatty streaks, advanced lesions, atheromas). The time window between excision of CA and beginning of gene transfer was between 3 and 6 hours for all the experiments. Specimens were cut into small pieces $(5 \times 5 \mathrm{~mm})$ under sterile conditions, while tissue pieces with large necrotic areas were avoided as the material was too friable. Internal mammary artery tissue segments were obtained from patients undergoing coronary artery bypass grafting. Atherosclerotic changes were excluded by a stereo microscope (Leitz, Heerbrugg, Switzerland) at 30× magnification. Rat aorta served as additional control for some experiments. Tissue pieces were incubated with a viral titer of $1 \times 10^{9} \mathrm{pfu} / \mathrm{ml}$ for 2 hours at $37^{\circ}$ and then kept in DMEM with $10 \%$ FCS for an additional 48 hours [20]. Tissue from CA, internal mammary artery and rat aorta was treated in an identical manner. Transduction was confirmed by staining of AdhPAP transfected specimens with NBT/BCIP (GIBCO) as described [23], and tissue specimens were analyzed by a stereo microscope (Leitz, Heerbrugg, Switzerland) at $30 \times$ magnification.

\section{Western blot analysis}

Western blot analysis was performed on tissue specimens as described [24]. $60 \mu \mathrm{g}$ protein were loaded per lane, resolved by SDS-PAGE under reducing conditions, blotted onto PVDF membranes and analyzed by chemiluminescence (Amersham). Equal loading of proteins was controlled for by staining with Ponceau $S$ as well as by blotting for $\alpha$-tubulin.

\section{Immunohistochemistry}

Tissue specimens were prepared as described [13].Specimens were incubated with anti-eNOS monoclonal antibody (N30020; Transduction Laboratories, Lexington, USA) at $4^{\circ}$ overnight. Immunostaining was performed with an FITC-conjugated goat anti-mouse antibody (F479; Dako, Glostrup, Denmark) at 1:10 dilution followed by counterstaining with Evans blue $0.1 \%$ (Merck, Darmstadt, Germany) and mounting in glycergel medium (Dako) [13]. Negative controls were obtained by replacing the primary antibody with an irrelevant anti CD18 antibody (1110; Monosan, Uden, Netherlands) as well as with antibodies for iNOS and nNOS (N32020 and N31020, respectively; Transduction Labo- ratories); positive controls were generated on human tonsil for eNOS, porcine pituitary gland for nNOS, and human macrophage cultures for iNOS [13].

\section{Nitrite release}

After transduction, tissue pieces were kept in DMEM with $20 \% \mathrm{FCS}$ at $37^{\circ}$ for 48 hours. This procedure has been shown to activate eNOS both in VSMC [25] and in vascular tissue [26]. Tissue pieces were homogenized and subsequently diluted in water. Quantitation of nitrite was performed as described [2].

\section{N0 release}

After transduction, tissue pieces were treated as described for nitrite measurement. NO release was stimulated by $10^{-5} \mathrm{M}$ calcium ionophore $\mathrm{A} 23187$, and $\mathrm{NO}$ was measured by a porphyrinic microsensor as described [28].

\section{eNOS activity}

Vessels were homogenized in $600 \mu \mathrm{l}$ of a solution containing $50 \mathrm{mM}$ Tris $\mathrm{pH} 7.4,250 \mathrm{mM}$ sucrose, and $2 \mathrm{mM}$ EDTA. $50 \mu \mathrm{l}$ of homogenate was incubated at room temperature in $200 \mu \mathrm{l}$ incubation medium with or without 2 mM L-NAME, containing $1 \mathrm{mM}$ nicotine adenine dinucleotide phosphate (NADPH), $4 \mathrm{mM} \mathrm{CaCl}_{2}, 1 \mathrm{mM}$ DTT, $15 \mu \mathrm{M}$ tetrahydrobiopterin, $10 \mu \mathrm{M}$ flavin adenine dinucleotide (FAD), $10 \mu \mathrm{M}$ flavin mononucleotide (FMN), 10 $\mu \mathrm{g} / \mathrm{ml}$ calmodulin, $0.2 \mu \mathrm{Ci} 3 \mathrm{H}$-arginine, and $50 \mu \mathrm{M}$ unlabeled L-arginine. The reaction was stopped after $1 \mathrm{~h}$ by addition of HEPES (100 mM), EDTA (4 mM), EGTA (2 $\mathrm{mM}) \mathrm{pH} 5.5$ containing unlabeled amino acid markers. For some experiments, calcium was omitted in the buffer. Radiolabeled arginine was separated from citrulline on silica gel thin-layer chromatography plates using chloroform:methanol: $\mathrm{NH}_{4} \mathrm{OH}$ :water 1:4:2:1 $\mathrm{vol} / \mathrm{vol}$ as solvent and developed with fluoraldehyde-ophthaladehyde reagent. The relevant bands were scraped from the plate and counted in a scintillation counter. Citrulline production was expressed as $\mathrm{dpm}$ citrulline/h/g wet weight.

\section{Superoxide release}

After transduction, tissue pieces were kept in DMEM with $20 \% \mathrm{FCS}$ at $37^{\circ}$ for 48 hours. $\mathrm{O}_{2}^{-}$production was measured by coelenterazine chemoluminescence as described using a Turner Design Model TD-20/20 luminometer (Turner Designs, Sunnyvale, CA) [27]. $\mathrm{O}_{2}^{-}$re- 
lease rate was expressed as relative light units/minute/ mg dry weight. Absolute values of $\mathrm{O}_{2}^{-}$release were determined with known quantities of xanthine and xanthine oxidase by the SOD inhibitable cytochrome $\mathrm{c}$ reduction using the molar extinction coefficient for cytochrome c $\left(21 \mathrm{mmol} / \mathrm{l}^{-1} \cdot \mathrm{cm}^{-1}\right)$ and expressed as nmol/minute/mg dry weight [18].

\section{$\mathrm{BH}_{4}$ concentrations}

$\mathrm{BH}_{4}$ was measured in non-transduced, control vector treated, and eNOS vector treated carotid artery as described [10].

\section{Statistics}

Results represent the mean value of 5 to 8 experiments as indicated in the text. Data are expressed as mean \pm standard error of the mean (S.E.M.) and statistical com- parisons were performed using analysis of variance (ANOVA). A two-tailed $p$ value of less than 0.05 was considered to indicate a significant difference.

\section{Results}

\section{Expression of eNOS}

Adenoviral transduction of human CA was assessed by human placental alkaline phosphatase (hPAP). NBT/BCIP staining revealed the presence of functional hPAP in CA transduced with hPAP adenovirus (hPAP), but not with control adenovirus $(\triangle \mathrm{E} 1)$ nor under nontransduced conditions indicating good transduction using this vector (Fig. 1A). eNOS expression in human CA after adenoviral transduction was first examined by Western blot analysis, which demonstrated a high expression after transduction with the eNOS adenovirus (eNOS), while the protein was barely detectable in the control adenovirus group $(\Delta \mathrm{E} 1)$ nor under non-trans-
Fig. 1 A. Placental alkaline phosphatase (hPAP) expression in transduced atherosclerotic human carotid artery (CA). Intimal side observed by stereomicroscope at 30x magnification. NBT/BCIP staining demonstrates hPAP in CA transduced with hPAP adenovirus (hPAP), but not control adenovirus $(\triangle \mathrm{E} 1)$ nor under non-transduced conditions. B. Endothelial nitric oxide synthase (eNOS) expression in CA. Western blot analysis demonstrates eNOS in CA transduced with eNOS adenovirus (eNOS), but not control adenovirus ( $\triangle \mathrm{E} 1)$ nor under non-transduced conditions. $\mathbf{C}$. eNOS expression in CA. Immunohistochemical analysis demonstrates eNOS protein in CA transduced with eNOS adenovirus (eNOS), while there is only very faint staining with control adenovirus $(\Delta \mathrm{E} 1)$ and no staining under non-transduced conditions (lower row). The presence of an intact endothelium is demonstrated by staining for von Willebrand Factor (middle row). An H\&E staining is presented as well (upper row). Magnification 400x
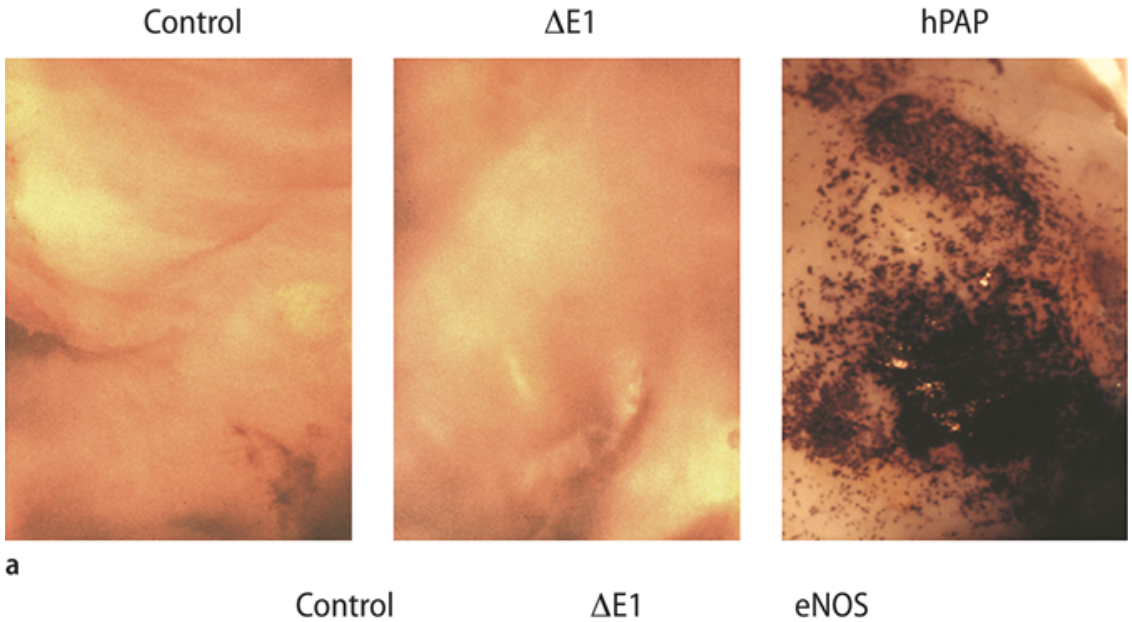

$\Delta \mathrm{E} 1$

eNOS
$H \& E$

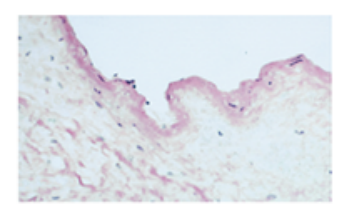

vWF

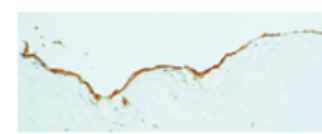

eNOS

c

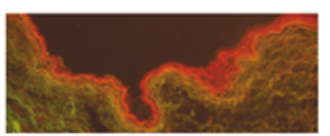

$\Delta \mathrm{E} 1$
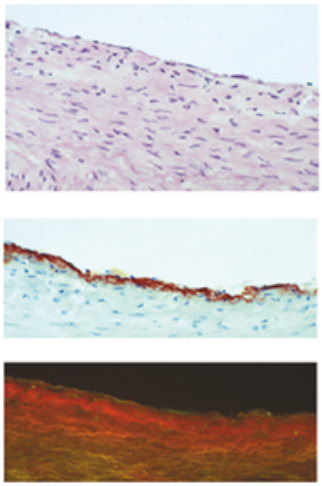

eNOS
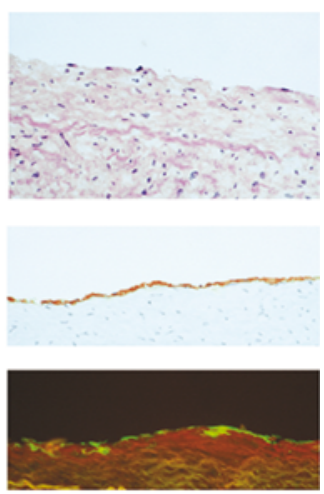
duced conditions (Fig. 1B). Immunohistochemical analysis of eNOS expression revealed a strong signal in endothelial and to a lesser degree in subendothelial cells of transduced specimens. Consistent with the Western blots, no significant staining was detected in control adenovirus transduced tissues or in non-transduced samples (Fig. 1C). This pattern of eNOS expression in atherosclerotic carotid artery was observed in most transduced specimens; however, in 2 out of 10 samples, eNOS expression was not clearly increased as compared to control specimens, which is consistent with the heterogenic morphology of the atherosclerotic tissue. Expression of iNOS and nNOS was examined in serial sections; no staining was observed in non-transduced and transduced specimens (data not shown).

Western blotting revealed that eNOS expression was 8.75-fold higher in non-atherosclerotic human internal mammary artery (MA) as compared side by side to atherosclerotic carotid artery $(\mathrm{p}<0.05 ; \mathrm{n}=4-5$; Fig. 2, left panel). Indeed, only prolonged exposure times permitted to detect a signal for eNOS in the carotid artery samples. After adenoviral transduction, eNOS expression increased by 10.7 -fold in MA ( $p<0.01$ for control vs. eNOS and for $\Delta \mathrm{E} 1$ vs. eNOS; $\mathrm{n}=5$; Fig. 3, left panel) and by 9.9fold in CA ( $p<0.05$ for control vs. eNOS and for $\Delta \mathrm{E} 1 \mathrm{vs.}$ eNOS; $\mathrm{n}=5$; Fig. 3 , right panel). Moreover, eNOS expression was similar in MA and CA transduced with eNOS $(\mathrm{p}=0.55 . ; \mathrm{n}=5)$.

\section{Release of NO}

NO release from CA after eNOS gene transfer was first assessed by measuring nitrite $\left(\mathrm{NO}_{2}^{-}\right)$tissue levels. 48 hours after transduction, the cumulative nitrite level was $0.378 \pm 0.249 \mu \mathrm{mol} / \mathrm{g}$ for non-transduced conditions, $0.854 \pm 0.495 \mu \mathrm{mol} / \mathrm{g}$ for control adenovirus $(\Delta \mathrm{E} 1)$, and $1.110 \pm 0.696 \mu \mathrm{mol} / \mathrm{g}$ for eNOS adenovirus (eNOS) ( $\mathrm{p}=0.76$ for control vs. eNOS; $\mathrm{p}=0.46$ for control vs. $\Delta \mathrm{E} 1$; $\mathrm{p}=0.70$ for $\mathrm{Ad} \Delta \mathrm{E} 1 \mathrm{vs}$. AdeNOS; $\mathrm{n}=8$; Fig. 4 , right panel). To compare NO release from CA with that from an arterial tissue without atherosclerotic changes, a parallel set of experiments was performed in rat aorta. In contrast to CA, eNOS gene transfer enhanced NO release from this tissue. Indeed, 48 hours after transduction, the nitrite tissue level was $0.914 \pm 0.562 \mu \mathrm{mol} / \mathrm{g}$ for non-trans-
Fig. 2 Endothelial nitric oxide synthase (eNOS) expression and nitric oxide (NO) release in human arteries. eNOS expression (left panel) is determined by Western blots and indicated in arbitrary densitometric units; expression is higher in internal mammary artery (MA) as compared to atherosclerotic carotid artery (CA). NO release (right panel) is measured by a porphyrinic microsensor and it is higher in MA than CA

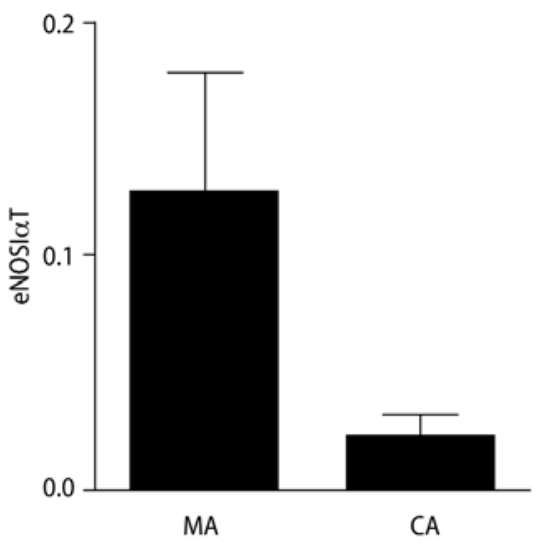

Fig.3 Endothelial nitric oxide synthase (eNOS) expression in transduced human arteries. Expression is determined by Western blots and indicated in arbitrary densitometric units. The eNOS signal is related to that of $\alpha$-tubulin ( $\alpha \mathrm{T}$ ) as loading control. eNOS expression is high in internal mammary artery (MA) and atherosclerotic carotid artery $(\mathrm{CA})$ transduced with eNOS adenovirus (eNOS), while a weak signal is detected in both vessels with control adenovirus ( $\Delta \mathrm{E} 1)$ or under non-transduced conditions
MA
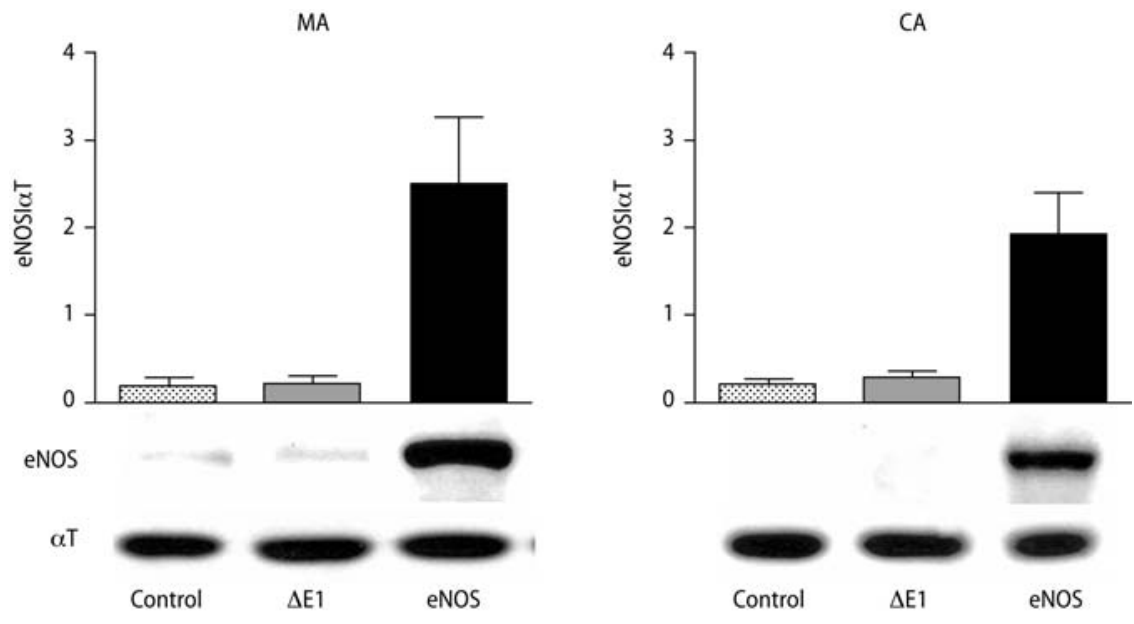

CA

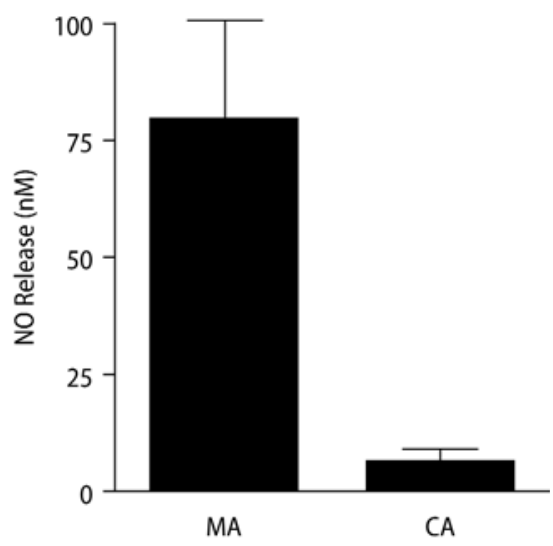


duced conditions, $6.590 \pm 1.362 \mu \mathrm{mol} / \mathrm{g}$ for control adenovirus $(\Delta \mathrm{E} 1)$, and $11.112 \pm 1.493 \mu \mathrm{mol} / \mathrm{g}$ for eNOS adenovirus (eNOS) $(p=0.0001$ for control vs. eNOS; $p<0.01$ for control vs. $\Delta \mathrm{E} 1 ; \mathrm{p}<0.05$ for $\Delta \mathrm{E} 1$ vs. eNOS; $\mathrm{n}=5$; Fig. 4 , left panel). An effect of control adenovirus on NO release after eNOS transduction has been observed in non-atherosclerotic tissue in previous studies as well $[25,26]$. To confirm that eNOS gene transfer did not affect NO production in CA, the release of $\mathrm{NO}$ was also measured by a porphyrinic microsensor upon stimulation with $10^{-5} \mathrm{M}$ calcium ionophore A23187. All the measurements were performed within 10 seconds. NO release was similar under non-transduced conditions and in tissue treated with control adenovirus $(\triangle \mathrm{E} 1)$ or with eNOS adenovirus (eNOS) $(\mathrm{p}=0.82$ for control vs. $\Delta \mathrm{E} 1$; $\mathrm{p}=0.45$ for control vs. eNOS; $\mathrm{p}=0.92$ for $\Delta \mathrm{E} 1$ vs. eNOS; $\mathrm{n}=8$; Fig. 4, upper insert).

To study NO production in a non-atherosclerotic human tissue as well, NO release from transduced MA was examined. As compared to control conditions (100\%; $85 \pm 27 \mathrm{nM})$, NO production of this tissue was $89 \pm 22 \%$ $(80 \pm 40 \mathrm{nM})$ for control adenovirus $(\Delta \mathrm{E} 1)$ and $254 \pm 40 \%$ (228 $\pm 106 \mathrm{nM})$ for eNOS adenovirus (eNOS) $(\mathrm{p}<0.005$ for control vs. eNOS; $\mathrm{p}<0.005$ for $\Delta \mathrm{E} 1$ vs. eNOS; $\mathrm{p}=0.95$ for control vs. $\Delta \mathrm{E} 1 ; \mathrm{n}=4$; Fig. $5 \mathrm{~A}$ ). MA NO production under non-transduced conditions was $85 \pm 27 \mathrm{nM}$ and hence much higher as compared to CA $(5 \pm 3 n M ; n=9 ; p=0.001 ;$ Fig. 2 , right panel). Again, NO production in CA was not affected by transduction of eNOS, while that in MA increased (Fig. 5B).

To assess whether the atherosclerotic tissue deteriorated during the $48 \mathrm{~h}$ incubation period, NO release was compared in freshly isolated versus incubated CA and found to be identical (fresh: $8.0 \pm 4.6 \mathrm{nM}$; incubated: $7.5 \pm 2.6 \mathrm{nM} ; \mathrm{n}=4 ; \mathrm{p}=0.93)$. Consistent with a minimal NO production, eNOS activity was barely detectable in $\mathrm{CA}$; indeed, the values were several thousand fold lower as compared to non atherosclerotic arterial tissue from various species including humans $[8,10]$. In the absence of calcium, no enzyme activity was detected, indicating that iNOS does not contribute to this activity. Enzyme activity was not affected by transduction $(p=n . s$. for non-transduced vs. eNOS; $\mathrm{p}=$ n.s. for non-transduced vs. $\Delta \mathrm{E} 1 ; \mathrm{p}=$ n.s. for $\Delta \mathrm{E} 1$ vs. eNOS; $\mathrm{n}=5$; Table). To address whether cofactor deficiency in the atherosclerotic tissue was responsible for the lack of enhanced $\mathrm{NO}$ production after transduction, tissue concentrations of $\mathrm{BH}_{4}$ were determined. $\mathrm{BH}_{4}$ concentrations were similar for nontransduced $(3.17 \pm 1.18 \mathrm{pmol} / \mathrm{mg}), \Delta \mathrm{E} 1$-transduced $(6.20 \pm 2.27 \mathrm{pmol} / \mathrm{mg})$, and eNOS-transduced tissue (7.63 $\pm 4.72 \mathrm{pmol} / \mathrm{mg} ; \mathrm{n}=3 ; \mathrm{p}=$ n.s.). Moreover, tissue specimens were incubated with $\mathrm{BH}_{4}\left(10^{-4} \mathrm{M}\right), \mathrm{FAD}$ $\left(5 \times 10^{-6} \mathrm{M}\right)$, FMN $\left(5 \times 10^{-6} \mathrm{M}\right)$, NADPH $\left(5 \times 10^{-4} \mathrm{M}\right)$, and L-arginine $\left(10^{-4} \mathrm{M}\right)$ for 3 hours before NO was measured. NO release was not altered in all three experimental groups (non-transduced, $\triangle \mathrm{E} 1$, eNOS) as compared to conditions without cofactor addition $(n=4 ; \mathrm{p}$ values ranging from 0.59 to 0.99 ; Table). Similar results were obtained when these cofactors were present during the $48 \mathrm{~h}$ period between transfection and measurement of NO release (all values $<15 \mathrm{nM} N O ; n=4 ; \mathrm{p}$ values ranging from 0.67 to 0.93 ; data not shown). Further, no change in NO release was observed when sepiapterin instead of $\mathrm{BH}_{4}$ was used (all values $<15 \mathrm{nM} \mathrm{NO}$; $=2$; data not shown).

\section{Release of $\mathrm{O}_{2}^{-}$}

To analyze whether increased $\mathrm{O}_{2}^{-}$generation in transduced CA could lead to enhanced catabolism of NO, the release of $\mathrm{O}_{2}{ }^{-}$was measured by coelenterazine chemoluminescence. $\mathrm{O}_{2}{ }^{-}$production was $0.245 \mathrm{nmol} / \mathrm{min} / \mathrm{mg}$ dry weight for non-transduced conditions, 0.335 $\mathrm{nmol} / \mathrm{min} / \mathrm{mg}$ dry weight for control adenovirus $(\Delta \mathrm{E} 1)$, and $0.254 \mathrm{nmol} / \mathrm{min} / \mathrm{mg}$ dry weight for eNOS aden-
Fig. 4 Nitric oxide ( $\mathrm{NO}$ ) and superoxide $\left(\mathrm{O}_{2}^{-}\right)$production in transduced atherosclerotic human carotid artery (CA). Nitrite production is similar in CA transduced with eNOS adenovirus (eNOS) as compared to control adenovirus $(\Delta \mathrm{E} 1)$ and non-transduced conditions. In contrast, nitrite production is significantly higher in rat aorta transduced with eNOS as compared to $\Delta \mathrm{E} 1$ and non-transduced conditions. Nitric oxide (NO) production is shown in the upper insert and is similar in CA transduced with eNOS as compared to $\triangle E 1$ and non-transduced conditions. Superoxide $\left(\mathrm{O}_{2}^{-}\right)$production is shown in the lower insert and is also similar in CA transduced with eNOS as compared to $\Delta \mathrm{E} 1$ and non-transduced conditions
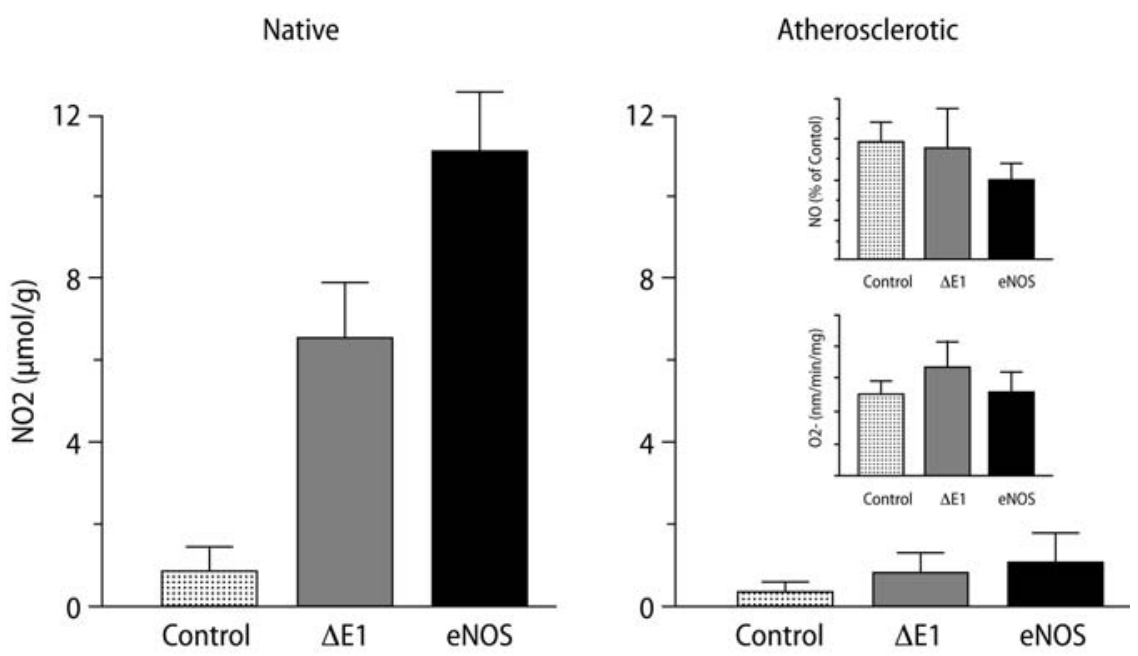
Fig. 5 Release of nitric oxide (NO) in transduced human arteries measured by porphyrinic microsensor. A. NO release is higher in internal mammary artery (MA) transduced with endothelial nitric oxide synthase (eNOS) adenovirus as compared to control adenovirus $(\Delta \mathrm{E} 1)$ or to control conditions. Left panel: original recording; right panel: average values of 4 independent experiments. B. NO release is higher in MA as compared to atherosclerotic carotid artery under nontransduced conditions (left panel), after treatment with $\triangle \mathrm{E} 1$ (middle panel), and after transduction with eNOS (right panel)
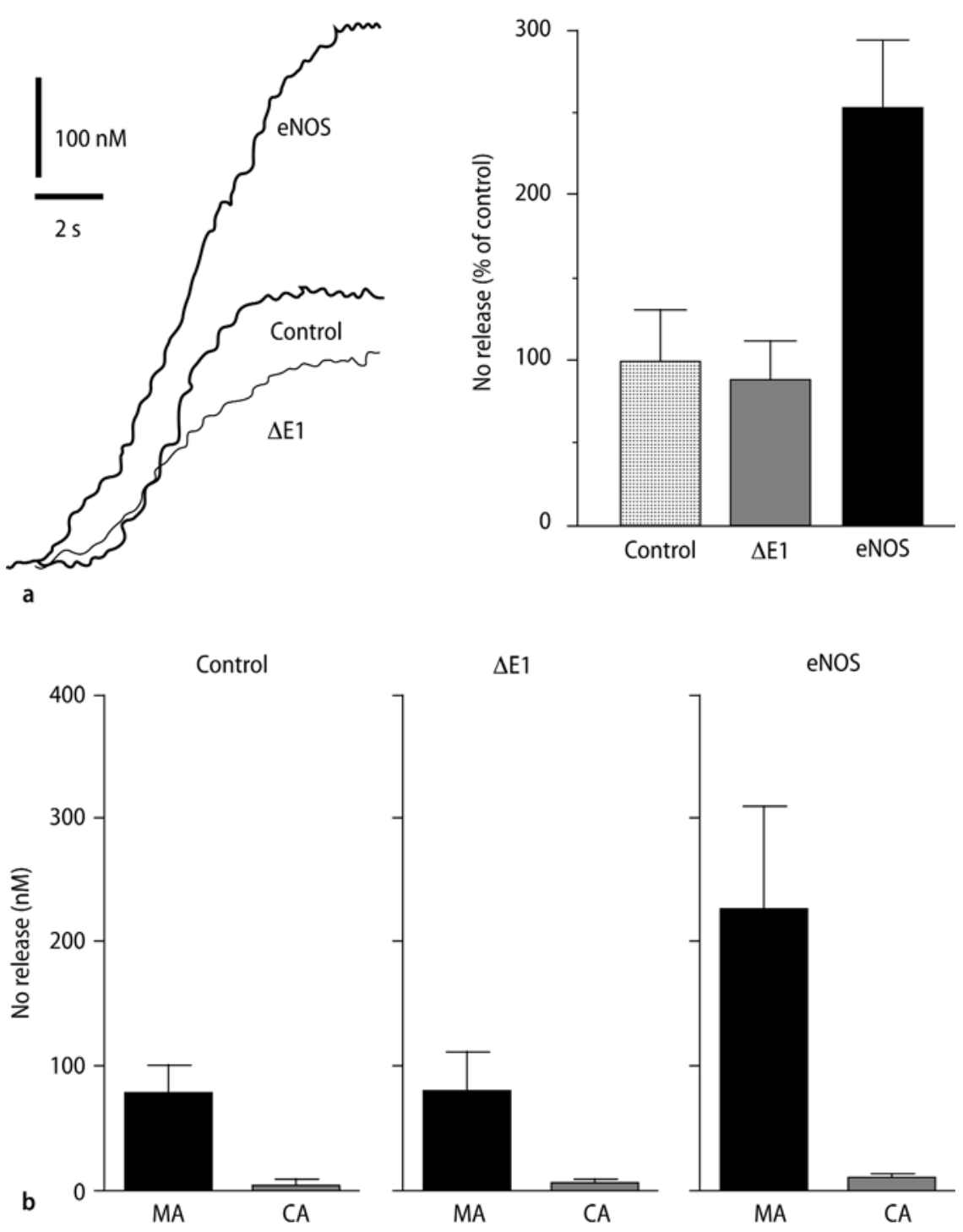

ovirus (eNOS) ( $p=0.97$ for non-transduced vs. eNOS; $\mathrm{p}=0.59$ for non-transduced vs. $\Delta \mathrm{E} 1 ; \mathrm{p}=0.71$ for $\Delta \mathrm{E} 1 \mathrm{vs}$. eNOS; $n=5$; Fig. 4 lower insert). To address whether superoxide generated in the atherosclerotic tissue reacted with NO, the porphyrinic microsensor measurement was repeated in the presence of superoxide dismutase (SOD; $25 \mathrm{U} / \mathrm{ml}$ ) or polyethylene glycol superoxide dismutase (PEG-SOD; $300 \mathrm{U} / \mathrm{ml}$ ). NO release was not altered in all three experimental groups (non-transduced, $\triangle \mathrm{E} 1, \mathrm{eNOS}$ ) as compared to conditions without addition of SOD or PEG-SOD ( $\mathrm{p}$ values ranging from 0.45 to 0.99 ; $\mathrm{n}=5$; Table). To assess whether $\mathrm{H}_{2} \mathrm{O}_{2}$ was involved in $\mathrm{NO}$ breakdown, the microsensor measurement was repeated in the presence of PEG-catalase $(1000 \mathrm{U} / \mathrm{ml})$. NO release was not altered in all three experimental groups (nontransduced, $\Delta \mathrm{E} 1$, eNOS) as compared to conditions without addition of PEG-catalase ( $p$ values ranging from
0.43 to $0.95 ; \mathrm{n}=4$; Table). As a positive control for the action of PEG-SOD and PEG-catalase preparations, the effect of $300 \mathrm{U} / \mathrm{ml}$ of PEG-SOD and $1000 \mathrm{U} / \mathrm{ml}$ of PEGcatalase on conversion of dichlorodihydrofluorescein diacetate to dichlorodihydrofluorescein was determined. PEG-SOD reduced the conversion induced by 1 $\mathrm{mM}$ SIN- 1 to $26 \pm 0.5 \%$ of control $(\mathrm{p}<0.001 ; \mathrm{n}=6)$. PEGcatalase also inhibited conversion induced by $1 \mathrm{mM}$ $\mathrm{H}_{2} \mathrm{O}_{2}(54 \pm 0.6 \%$ of control; $\mathrm{p}<0.0001 ; \mathrm{n}=6)$.

\section{Discussion}

This study demonstrates that adenoviral transduction of atherosclerotic human CA results in marked eNOS expression without enhancing NO release, indicating that the recombinant enzyme is dysfunctional in ather- 
Table Activity of endothelial nitric oxide synthase (NOS) and release of nitric oxide (NO) in the presence of cofactors, superoxide dismutase (SOD; $25 \mathrm{U} / \mathrm{ml}$ ), PEGSOD $(300 \mathrm{U} / \mathrm{ml})$, PEG-catalase $(1000 \mathrm{U} / \mathrm{ml})$ in transduced atherosclerotic human carotid artery (CA). NOS activity was determined by citrulline assay, NO production by porphyrinic microsensor. The cofactors $\mathrm{L}$-arginine $\left(10^{-4} \mathrm{M}\right), \mathrm{BH}_{4}\left(10^{-4} \mathrm{M}\right)$, FAD $\left(5 \times 10^{-6} \mathrm{M}\right), \mathrm{FMN}\left(5 \times 10^{-6} \mathrm{M}\right), \mathrm{NADPH}\left(5 \times 10^{-4} \mathrm{M}\right)$ were added for 30 minutes prior to measurement. All the treatments did not significantly improve NOS activity or NO release $(p=n . s$.

\begin{tabular}{lrll}
\hline Parameter & Control & \multicolumn{1}{l}{ ME1 } & \multicolumn{1}{l}{ eNOS } \\
\hline NOS activity (pmol NO/h/g protein) & $4.6 \pm 4.6$ & $27.1 \pm 10.3$ & $24.3 \pm 14.1$ \\
NO release without cofactors (nM) & $5.0 \pm 5.0$ & $5.8 \pm 3.9$ & $10.8 \pm 4.0$ \\
NO release with cofactors (nM) & $13.0 \pm 6.0$ & $8.3 \pm 5.0$ & $5.0 \pm 5.0$ \\
NO release without SOD (nM) & $5.2 \pm 5.2$ & $2.0 \pm 2.0$ & $7.8 \pm 5.2$ \\
NO release with SOD (nM) & $5.2 \pm 5.2$ & $9.8 \pm 6.0$ & $5.2 \pm 5.2$ \\
NO release without PEG-SOD (nM) & $4.0 \pm 2.3$ & $6.6 \pm 4.2$ & $8.5 \pm 3.1$ \\
NO release with PEG-SOD (nM) & $6.6 \pm 3.8$ & $4.0 \pm 2.3$ & $10.1 \pm 3.5$ \\
NO release without PEG-catalase (nM) & $5.3 \pm 1.8$ & $1.8 \pm 1.8$ & $2.8 \pm 2.8$ \\
NO release with PEG-catalase (nM) & $5.0 \pm 5.0$ & $8.3 \pm 3.1$ & $3.5 \pm 3.5$ \\
\hline
\end{tabular}

osclerotic human vessels. Expression of the transduced genes in CA was observed in both endothelium and subendothelial cells. After eNOS transduction, VSMC and adventitial fibrocytes can release NO [8, 25]; thus, medial and adventitial cells may contribute to NO release in transduced vessels. Therefore, endothelial damage or even denudation during PTCA is not a reason to refrain from eNOS gene transfer. However, the lack of NO release indicates that eNOS gene transfer is not a reasonable gene therapy strategy for restenosis or atherosclerotic vascular disease.

A higher eNOS expression in transduced atherosclerotic CA as compared to control tissue was observed in 8 out of 10 samples. In the other two samples, no clear increase in eNOS expression was present as compared to control. Hence, transfection of atherosclerotic CA is somewhat variable, presumably due to its morphological heterogeneity. Nevertheless, most of the samples exhibited a higher eNOS expression as compared to control. Therefore, the missing increase in NO release in all the transduced samples can not be explained by variability of transfection. NO production after eNOS transduction was determined by both nitrite formation and NO release. Neither method detected an enhanced NO production in transduced CA as compared to control tissue. Rat aorta and human internal mammary artery served as non-atherosclerotic controls for $\mathrm{NO}$ formation after eNOS transduction. These controls were chosen because of the obvious difficulties to obtain non-atherosclerotic human CA. Experiments were performed in parallel with those in CA and revealed both an enhanced eNOS expression and NO production after eNOS transduction, demonstrating that overexpression of eNOS enhances NO release only in non-atherosclerotic tissue; therefore, similar to endogenous eNOS, the transduced enzyme seems to be dysfunctional in atherosclerotic tissue. The lack of NO release is not only consistent with dysfunction of eNOS, but also with absence of iNOS expression in the CA tissue; as the specimens originated from long-standing lesions with presumably stable plaques, inflammation probably does not play a major role in these lesions any longer.

In the rat aorta, the control adenovirus had some effect on nitrite formation, suggesting that the vector induces the endogenous enzyme. Consistent with this interpretation, there was a very faint staining for eNOS in the $\Delta \mathrm{E} 1$ transduced CA. As nitrite formation in the latter was neither altered by $\Delta \mathrm{E} 1$ nor eNOS adenovirus, atherosclerosis may induce a similar functional defect of both the endogenous and the recombinant enzyme. However, the control vector did not have any effect on NO formation as determined by the porphyrinic microsensor in the human internal mammary artery. This observation offers the alternative explanation that the effect of $\Delta \mathrm{E} 1$ on nitrite formation does not depend on NO or, with lower probability, that it is influenced by the type of species or vessel involved.

Activity of eNOS in CA was determined by a highly sensitive modification of the citrulline assay and was almost undetectable both under control conditions and after eNOS transduction. Indeed, the values were several thousand fold lower as compared to non-atherosclerotic arterial tissue from various species including humans $[5,16]$. This observation demonstrates that eNOS activity is not enhanced after transduction and is consistent with the minimal NO release from the atherosclerotic tissue. For catalysis of NO formation from L-arginine, eNOS requires several cofactors. Indeed, FAD and FMN are necessary for electron transport from NADPH to oxygen, while $\mathrm{BH}_{4}$ is required for efficient generation of NO from reduced oxygen and L-arginine. Deficiency of these cofactors may hamper the function of the endogenous as well as the recombinant enzyme. In fact, atherosclerotic vessels contain lower cofactor concentrations and release less NO as compared to normal vessels, and cofactor infusion can improve NO formation [7, 22, 31]. Hence, $\mathrm{BH}_{4}$ concentrations in CA after eNOS transduction were determined. Concentrations of the cofactor did not differ in transduced as compared to control tissue. Further, NO release from CA after eNOS transduction was examined in the presence of cofactor supplementation. Under these conditions, however, NO release did not differ in transduced as compared to control tissue. Although some degradation of cofactors in culture can not be excluded, these data suggest that cofactor deficiency alone can not account for the dysfunction of the recombinant enzyme. Hence, the lack of eNOS activity in transduced atherosclerotic tissue must be related to other mechanisms as well. Indeed, it is conceivable that the presence of oxidized LDL in the atherosclerotic tissue may impair signal transduction activation of eNOS; 
furthermore, competitive inhibitors of eNOS such as ADMA may be synthesized in the endothelium causing decreased eNOS activity [4].

In case of suboptimal $\mathrm{BH}_{4}$ concentrations, uncoupling of eNOS occurs, and the enzyme itself becomes a source of $\mathrm{O}_{2}{ }^{-}$. Hence, the lack of an increase in NO production after eNOS transduction may be related to increased $\mathrm{O}_{2}^{-}$formation resulting in $\mathrm{NO}$ catabolism. Therefore, $\mathrm{O}_{2}^{-}$generation in CA was determined. $\mathrm{O}_{2}{ }^{-}$release did not differ in eNOS transduced tissue as compared to control conditions, indicating that enhanced NO catabolism is not a probable reason for the unaltered NO release after transduction, and supporting the interpretation that cofactor deficiency can not be the sole reason for the dysfunction of recombinant eNOS. Consistent with these observations, NO production remained identical in the presence of SOD and PEG-SOD. Similarly, PEG-catalase did not affect the formation of $\mathrm{NO}$, indicating that $\mathrm{NO}$ catabolism by $\mathrm{H}_{2} \mathrm{O}_{2}$ can be excluded as a reason for the unaltered NO release after transduction as well.

In theory, eNOS gene transfer is a very reasonable therapeutic strategy for vascular disease, as NO does not only inhibit VSMC proliferation, but also impairs thrombus formation eliminating a major source of mitogens for VSMC, and interferes with adhesion molecule expression as well as leucocyte invasion $[3,12]$. In addition, expression of eNOS is reduced in atherosclerotic tissue, demanding substitution by a recombinant enzyme [17]. For the treatment of restenosis, however, eNOS gene transfer is unlikely to provide clinical bene- fit; such vessels are severely atherosclerotic, and, according to our data, transduction would result in expression of an inactive enzyme. Since eNOS gene transfer has been described to reduce vascular smooth muscle cell proliferation [6] and restenosis in a pig and a mouse model $[15,29,30]$, the inactivity of recombinant eNOS in the human CA is surprising; however, differences in gender, in the degree of atherosclerosis, and/or in the pathogenesis of atherosclerosis may well account for the different activity of recombinant eNOS in these models and the human tissue. Thus, transduction of a gene can result in unexpected features in the respective human tissue, indicating that ex vivo studies with the relevant tissue should be performed before starting clinical trials. In contrast to restenosis, coronary artery bypass graft disease still represents a promising target for eNOS gene transfer. Indeed, the saphenous vein is not atherosclerotic when implanted as bypass graft. Moreover, eNOS transduction inhibits biological features of bypass graft disease in the human saphenous vein ex vivo [26]. Therefore, in its current state, successful application of gene transfer technology for treating vascular diseases requires a specifically tailored strategy, which does not only take into account efficieny of transduction and duration of expression, but also the biological characteristics of the respective human tissue.

Acknowledgements This study was supported by the Swiss National Science Foundation (Grant Nr. 31-47119.96 and 32-51069.97), Swiss Heart Foundation, Hartmann Müller Foundation.

\section{References}

1. Alcorn JL, Gao E, Chen Q, Smith ME, Gerard RD, Mendelson CR (1993) Genomic elements involved in transcriptional regulation of the rabbit surfactant protein-A gene. Mol Endocrinol 7: 1072-1085

2. Barton M, Vos I, Shaw S, Boer P, d'Uscio LV, Gröne HJ, Rabelink TJ, Lattmann T, Moreau P, Luscher TF (2000) Dysfunctional renal nitric oxide synthase as a determinant of salt-sensitive hypertension: mechanisms of renal artery endothelial dysfunction and role of endothelin for vascular hypertrophy and glomerulosclerosis. J Am Soc Nephrol 11:835-846

3. Berendji-Grun D, Kolb-Bachofen V, Kroncke KD (2001) Nitric oxide inhibits endothelial IL-1(beta)-induced ICAM-1 gene expression at the transcriptional level decreasing Sp1 and AP-1 activity. Mol Med 7:748-754

4. Cannon RO (1998) Role of nitric oxide in cardiovascular disease: focus on the endothelium. Clinical Chemistry 44: 1809-1819
5. Chen AF, Jiang SW, Crotty TB, Tsutsui M, Smith LA, O’Brien T, Katusic ZS (1997) Effects of in vivo adventitial expression of recombinant endothelial nitric oxide synthase gene in cerebral arteries. Proc Natl Acad Sci USA 94: 12568-12573

6. Cooney R, Hynes SO, Duffy AM, Sharif F, O’Brien T (2006) Adenoviral-mediated gene transfer of nitric oxide synthase isoforms and vascular cell proliferation. J Vasc Res 43:462-472

7. Creager MA, Gallagher SJ, Girerd XJ, Coleman SM, Dzau VJ, Cooke JP (1992) L-arginine improves endothelium-dependent vasodilation in hypercholesterolemic humans. J Clin Invest 90: 1248-1253

8. d'Uscio LV, Baker TA, Mantilla CB, Smith L, Weiler D, Sieck GC, Katusic ZS (2001) Mechanism of endothelial dysfunction in apolipoprotein E-deficient mice. Arterioscler Thromb Vasc Biol 21: 1017-1022
9. Förstermann U (2006) Janus-faced role of endothelial NO synthase in vascular disease: uncoupling of oxygen reduction from NO synthesis and its pharmacological reversal. Biol Chem 387: 1521-1533

10. Fukushima T, Nixon JC (1980) Analysis of reduced forms of biopterin in biological tissues and fluids. Anal Biochem 102:176-188

11. Lauer T, Kleinbongard P, Preik M, Rauch BH, Deussen A, Feelisch M, Strauer B, Kelm M (2003) Direct biochemical evidence for eNOS stimulation by bradykinin in the human forearm vasculature. Basic Res Cardiol 98: 84-89

12. Lüscher TF, Vanhoutte PM (1990) The Endothelium: Modulator of Cardiovascular Function. CRC Press, Boca Raton

13. Meyer P, Champion C, Schlötzer-Schrehardt U, Flammer J, Haefliger IO (1999) Localisation of nitric oxide isoforms in porcine ocular tissues. Current Eye Research 18:375-380 
14. Mittereder N, March KL, Trapnell BC (1996) Evaluation of the concentration and bioactivity of adenovirus vectors for gene therapy. J Virology 70: 7498-7509

15. Mujynya-Ludunge $\mathrm{K}$, Viswambharan $\mathrm{H}$, Driscoll R, Ming X-F, von Segesser LK, Kappenberger L, Yang Z, Vassalli G (2005) Endothelial nitric oxide synthase gene transfer restores endothelium-dependent relaxations and attenuates lesion formation in carotid arteries in apolipoprotein E-deficient mice. Basic Res Cardiol 100:102-111

16. Nelson SH, Steinsland OS, Wang Y, Yallampalli C, Dong YL, Sanchez JM (2000) Increased nitric oxide synthase activity and expression in the human uterine artery during pregnancy. Circ Res 87 : 406-411

17. Oemar BS, Tschudi MR, Godoy N, Brovkovith V, Malinski T, Luscher TF (1998) Reduced endothelial nitric oxide synthase expression and production in human atherosclerosis. Circulation 97: 2494-2498

18. Ohara Y, Peterson TE, Harrison DG (1993) Hypercholesterolemia increases endothelial superoxide anion production. J Clin Invest 91:2546-2551

19. Ohno T, Gordon D, San H, Pompilij VJ, Imperiale MJ, Nabel GJ, Nabel EG (1994) Gene therapy for vascular smooth muscle cell proliferation after arterial injury. Science 265:781-784
20. Rekhter MD, Simari RD, Work CW, Nabel GJ, Nabel EG, Gordon D (1998) Gene transfer into normal and atherosclerotic human blood vessels. Circ Res 82:1243-1252

21. Ross R (1986) The pathogenesis of atherosclerosis - an update. N Engl J Med 314:488-500

22. Stroes ESG, Kastelein JJ, Cosentino F, Erkelens W, Wever R, Koomans $\mathrm{H}$, Luscher T, Rabelink T (1997) Tetrahydrobiopterin restores endothelial function in hypercholesterolemia. J Clin Invest 99:41-46

23. Tanner FC, Carr DP, Nabel GJ, Nabel EG (1997) Transfection of human endothelial cells. Cardiovasc Res 35:522-528

24. Tanner FC, Yang Z, Duckers E, Gordon D, Nabel GJ, Nabel EG (1998) Expression of cyclin-dependent kinase inhibitors in vascular disease. Circ Res 82: 396-403

25. Tanner FC, Meyer P, Greutert H, Champion C, Nabel EG, Luscher TF (2000) Nitric oxide modulates expression of cell cycle regulatory proteins: a cytostatic strategy for inhibiting human vascular smooth muscle cell proliferation. Circulation 101:1982-1989

26. Tanner FC, Largiadèr T, Greutert $\mathrm{H}$, Yang Z, Luscher TF (2004) Nitric oxide synthase gene transfer inhibits biological features of bypass graft disease in the human saphenous vein. J Thorac Cardiovasc Surg 127:20-26
27. Tarpey MM, White CR, Suarez E, Richardson G, Radi R, Freeman BA (1999) Chemiluminescent detection of oxidants in vascular tissue. Lucigenin but not coelenterazine enhances superoxide formation. Circ Res 84:1203-1211

28. Tschudi MR, Barton M, Bersinger NA, Moreau P, Cosentino F, Noll G, Malinski T, Luscher TF (1996) Effect of age on kinetics of nitric oxide release in rat aorta and pulmonary artery. J Clin Invest 98:899-905

29. Varenne O, Pislaru S, Gillijns H, van Pelt $\mathrm{N}$, Gerard RD, Zoldhelyi P, van de Werf F, Collen D, Hanssens SP (1998) Local adenovirus-mediated transfer of human endothelial nitric oxide synthase reduces luminal narrowing after coronary angioplasty in pigs. Circulation 98: 919-926

30. von der Thüsen JH, Fekkes ML, Passier $\mathrm{R}$, von Zonnefeld AJ, Mainfroid V, van Berkel TJC, Biessen EAL (2004) Adenoviral transfer of endothelial nitric oxide synthase attenuates lesion formation in a novel murine model of postangioplasty restenosis. Arterioscler Thromb Vasc Biol 24:357-362

31. Wever RMF, Luscher TF, Cosentino F, Rabelink T (1998) Atherosclerosis and the two faces of endothelial nitric oxide synthase. Circulation 97:108-112

32. Yang Z, Simari RD, Tanner FC, Stephan D, Nabel GJ, Nabel EG (1996) Gene transfer approaches to the regulation of vascular cell proliferation. Semin Intervent Cardiol 1:181-184 